This item was submitted to Loughborough's Research Repository by the author.

Items in Figshare are protected by copyright, with all rights reserved, unless otherwise indicated.

\title{
High-performance water-based barrier coatings for the corrosion protection of structural steel
}

PLEASE CITE THE PUBLISHED VERSION

https://doi.org/10.1002/stco.201710034

\section{PUBLISHER}

Wiley ( E Ernst \& Sohn Verlag für Architektur und technische Wissenschaften GmbH \& Co.

\section{VERSION}

AM (Accepted Manuscript)

\section{PUBLISHER STATEMENT}

This work is made available according to the conditions of the Creative Commons Attribution-NonCommercialNoDerivatives 4.0 International (CC BY-NC-ND 4.0) licence. Full details of this licence are available at: https://creativecommons.org/licenses/by-nc-nd/4.0/

\section{LICENCE}

CC BY-NC-ND 4.0

\section{REPOSITORY RECORD}

Dehan, Veronique, Elodie Bourgeat-Lami, Franck D'Agosto, Brendan Duffy, Andrea Fortini, Sharon Hilton, Kalliopi Krassa, et al.. 2017. "High-performance Water-based Barrier Coatings for the Corrosion Protection of Structural Steel”. figshare. https://hdl.handle.net/2134/26701. 


\title{
High Performance Waterbased Barrier Coatings for the Corrosion Protection of Structural Steel
}

V. Dehan, ${ }^{a}$ E. Bourgeat-Lami, ${ }^{b}$ F. D'Agosto, ${ }^{b}$ B. Duffy, ${ }^{c}$ A. Fortini, ${ }^{d}$ S. Hilton, ${ }^{e}$ J. L. Keddie, ${ }^{d}$ M. L. Koh, ${ }^{b}$ M. Lansalot, ${ }^{b}$ M. Lee, ${ }^{c}$ J. Lesage de la Haye, ${ }^{b}$ I. Martin-Fabiani, ${ }^{d, f}$ D. P. Mazeffa, ${ }^{e}$ R. P. Sear, ${ }^{d}$ M. Schulz, ${ }^{d}$ M. Sibbald, ${ }^{\mathrm{e}}$ B. Skerry, ${ }^{\mathrm{e}}$ and B. Thomas ${ }^{\mathrm{d}}$

a. ECCS, 32 Avenue des Obrages, 1200 Brussels, Belgium

b. Univ Lyon, Université Claude Bernard Lyon 1, CPE Lyon, CNRS, UMR 5265, Chemistry, Catalysis, Polymers \& Processes (C2P2), 43 Bd du 11 Novembre 1918, 69616 Villeurbanne, France

c. CREST, Dublin Institute of Technology, Dublin 6, Republic of Ireland

d. Department of Physics, University of Surrey, Guildford GU2 7XH, UK

e. Sherwin Williams Protective and Marine Coatings, Tower Works, Kestor Street, Bolton, B22 2AL

f. Department of Materials, Loughborough University, Loughborough, Leicestershire, LE11 3TU, UK

\begin{abstract}
This article provides an overview of the outcomes of a European-funded project called BarrierPlus. A new type of water-based barrier coating was developed for structural steel applications. Advantages of this coating include enhanced moisture resistance, low volatile organic compounds (VOCs), and onecomponent self-crosslinking free of isocyanates. To enable this performance, a latex polymer binder was uniquely designed without using soap-like molecules, known as surfactants, to form the dispersion. By minimizing surfactants in the coating, the barrier properties were significantly enhanced. The latex was successfully scaled up to $15 \mathrm{~kg}$ quantities by an SME, coatings formulations were scaled to pilot quantities, and a variety of characterization and coatings performance tests were completed. A life cycle assessment found that the BarrierPlus coating has a better environmental profile than an industry benchmark solventborne coating and showed promising results relative to commercial waterborne benchmarks.
\end{abstract}




\section{Introduction to the Problem of Corrosion of Structural Steel}

Steel is the world's most widely used construction material. It has been estimated that more than $90 \%$ of all metal surfaces are covered by paint or protective coatings.[1] Figure 1 illustrates how protective coatings are used across various sectors of industry.[2] Despite the wide use of coatings, corrosion of steel nevertheless has a detrimental economic cost to the world economy. The global cost of corrosion was recently estimated to be 2.5 trillion USD, which is approximately $3.4 \%$ of global Gross Domestic Product (GDP).[3] Within Europe, the costs associated with corrosion are 375 billion euros, which is approximately $3 \%$ of GDP. Hence, while protective coatings afford some measure of corrosion prevention and control, there is still a large market need for new high performance anti-corrosion coatings.

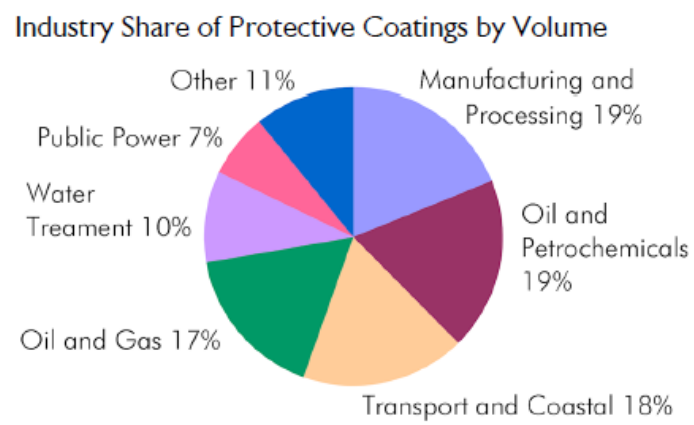

Fig. 1. Breakdown by sector of the Global protective coatings market.

\section{The Need for New Waterborne Coatings for Corrosion Protection of Steel}

Most of the existing coatings for steel have two key characteristics: (1) they are deposited by dissolving the polymer binder in an organic solvent (i.e., they are solvent borne); and (2) they are hardened or cured by mixing two components. Over $88 \%$ of the 
global protective coatings market is based on solvent-borne technologies.[3] A good example is a two component $(2 \mathrm{~K})$ solvent-borne acrylic polyurethane coating. In this system, one component is a polymer resin containing hydroxyl groups, which is dissolved in an organic solvent. Before the coating is applied to a metal surface, a second component consisting of isocyanate curing agents must be added to harden the coating.

Water-based coatings account for about $12 \%$ of the global protective coatings market, but only account for about $2 \%$ of the coatings used on steel.[3] Waterborne coatings offer several advantages over their solvent-borne counterparts. Easier clean up, generally requiring only water. Reduced volatile organic compound (VOC) emissions, which reduces potential impacts on the environment and on human health, while meeting restrictions on emissions established by legislation.[4] Additionally, waterborne coatings are not flammable, which ensures greater safety for manufacturing centres and workers.

Converting from a conventional $2 \mathrm{~K}$ technology to a one component $(1 \mathrm{~K})$ formulation offers additional benefits. The use of isocyanates and related curing chemicals is minimized or eliminated, thereby reducing chemical hazards. Additionally, there is reduced waste in $1 \mathrm{~K}$ formulations. In $2 \mathrm{~K}$ formulations, there is a short life of the product after it is mixed ("pot life"), whereas $1 \mathrm{~K}$ formulations overcome this challenge and can have a longer pot life.

A project funded through the European Commission's Seventh Framework Programme (FP7) aimed to develop 1K water-based anticorrosion coatings for structural steel with performance equal to conventional $2 \mathrm{~K}$ solvent-borne coatings. The project, which is called BarrierPlus, commenced in 2014 and drew to a close in 2017. The project's consortium consisted of two European associations (European Convention for Constructional Steelwork, Belgium and Norsk Stålforbund, Norway), two SMEs (Megara Resins, Greece and Tuinsa Norte, Spain), an industrial partner (Sherwin-Williams Protective and Marine Coatings, UK) 
and three research centres (Université Claude Bernard Lyon 1, CPE Lyon, CNRS, France; University of Surrey, UK, and CREST, Dublin Institute of Technology, Republic of Ireland). This consortium worked together to prepare unique polymers, formulate coatings, and characterize and test these systems against industry standard benchmark solvent-borne and water-based coatings.

\section{Film Formation of Waterborne Barrier Coatings}

The binder for the coatings of the BarrierPlus technology initially consists of spherical polymer particles in water. These latex particles undergo a film formation process, shown in Figure 2, to form a binder for a coating. The particles, typically a few hundred nanometers in diameter, are stabilized in water. When the liquid is cast on a surface, such as by spraying, the water evaporates and particles pack together. Because of the effects of surface energy, the particles deform from their spherical shape to fill the space around them. The polymer molecules within the latex particles mix with the molecules in neighbouring particles, so that the particles fuse together (i.e., coalesce) to create a homogeneous solid barrier on the coated surface.[5]

A major problem of the conventional waterborne binder technology is that the particles are stabilized by “water-loving” (or hydrophilic) molecules called surfactants. These hydrophilic soap-like molecules can be trapped at the boundaries of particles where they can create paths for water and salts to travel through a coating to corrode the underlying surface.[6] The surfactants can also decorate the coating surface where they can decrease the gloss, cause tackiness, and encourage dirt pick-up. 


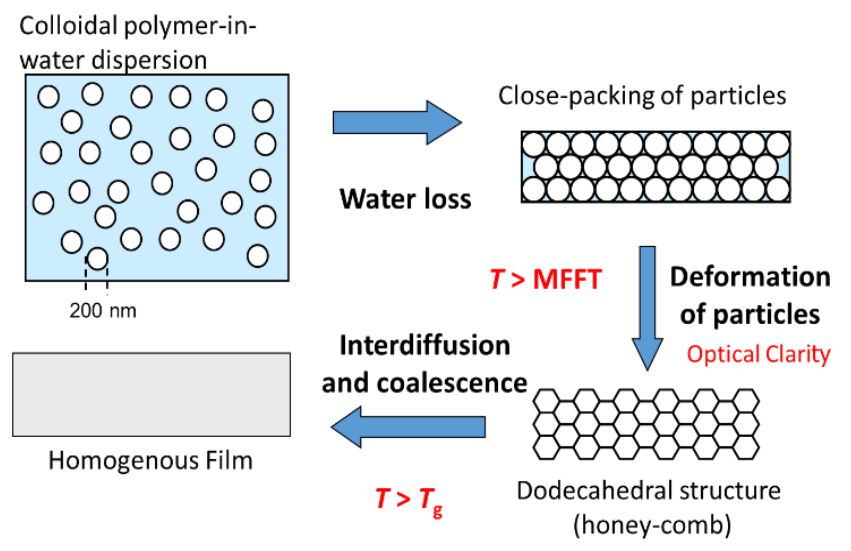

Fig. 2. Idealised view of the film formation process.

The new technology developed in the BarrierPlus project does not rely on soap-like surfactant molecules in the binder. Instead the particles are stabilized with polymer molecules.[7] Conventional waterborne binder particles are usually synthesized using emulsion polymerization in which the particles grow from clusters of the surfactant molecules. The surfactant covers the entire surface of the particles and offers stability in water. In contrast, the particles synthesized in the BarrierPlus project have spring-like polymer molecules on their surface, as is shown in Figure 3.

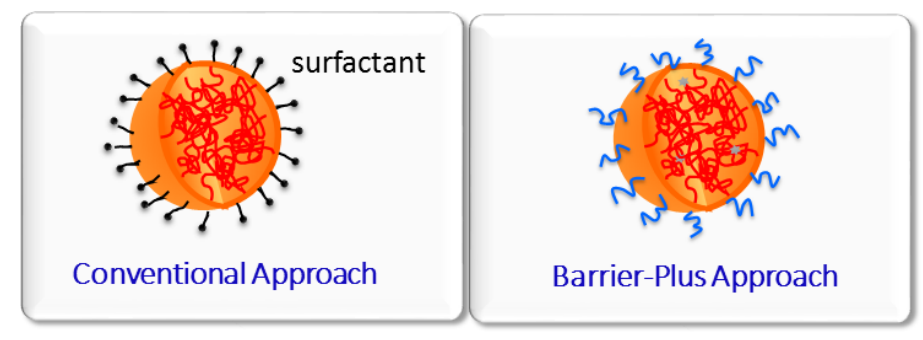

Fig. 3. A comparison of a conventional and a surfactant-free particle. Left: The conventional polymer particle is made via emulsion polymerization, and its surface is covered with surfactants (shown in black). Right: The surfactant-free particles made in the BarrierPlus project are stabilized by polymer molecules (shown as the blue curly lines) that extend into the surrounding water phase in the wet state.

The difference in the barrier coatings made from surfactant-free particles is immediately apparent when examined at the sub-micrometre scale using an atomic force 
microscope. Figure 4 shows a comparison. In a conventional waterborne coating, the surfactant is seen to accumulate in droplets on the film surface when aged at elevated temperatures. The surfactant-free coating made in the BarrierPlus project, on the other hand, has a more homogeneous surface structure and is more stable when aged.

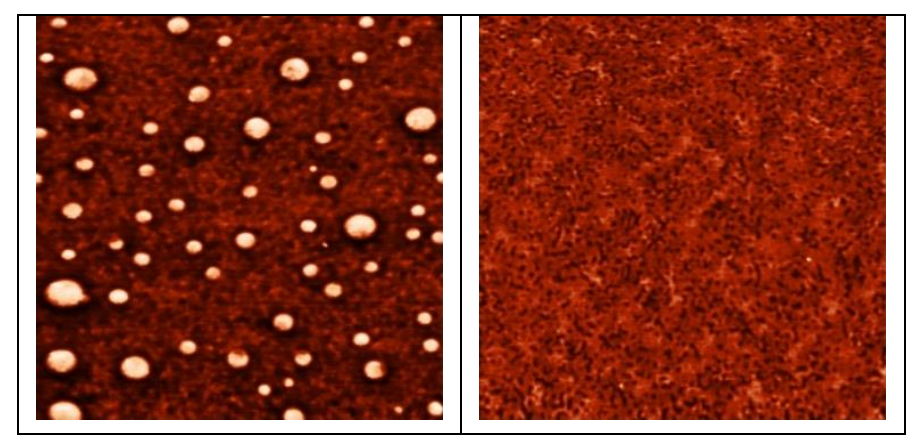

Fig. 4. Phase images of latex film surfaces obtained in an atomic force microscope. The image areas are $5 \mu \mathrm{m} \times 5 \mu \mathrm{m}$. At left side: a conventional waterborne binder (latex) surface after heating at a temperature of $200{ }^{\circ} \mathrm{C}$ for one hour. Droplets of sodium dodecyl sulphate surfactant (seen as the light-coloured circles) decorate the surface. At right side: the surface of a surfactant-free latex binder surface, which was developed in the BarrierPlus project, after being held at $200{ }^{\circ} \mathrm{C}$ for one hour. This structure is more homogeneous than the conventional binder and does not change over time in the same way.

\section{Better Properties from BarrierPlus Coatings}

The surfactant-free binder technology developed within the BarrierPlus project offers some obvious benefits in preventing the penetration of water through barrier coatings. When a conventional waterborne coating is soaked in water for prolonged times, it becomes opaque because water penetrates the coating where it creates small droplets that scatter light. This phenomenon is referred to as "water whitening" in the coatings literature.[8] The BarrierPlus coatings prevent water from penetrating, and they stay optically transparent even after soaking in water for up to three hours. Figure 5 compares the optical transmission spectra of a poor waterborne coating with a BarrierPlus coating. The superior properties of the BarrierPlus technology is apparent. 


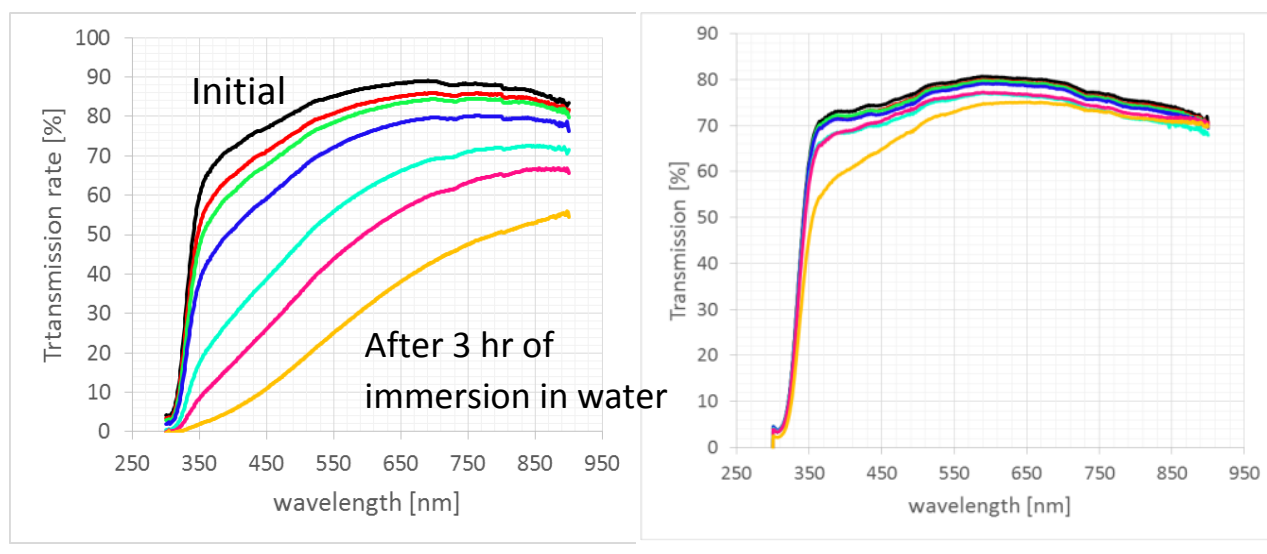

Fig. 5. Optical transmission of barrier coatings over time when soaked in water. The visible region of the spectrum is in the wavelength range from approximately $400 \mathrm{~nm}$ to $750 \mathrm{~nm}$. In both sets of spectra, the black line is obtained from the initial coating; the yellow line is obtained after three hours of soaking in water. The intermediate times are represented by the other colours. Left: A poor water barrier coating becomes opaque over time as water is absorbed in the film. Right: The optical transparency of a coating from the BarrierPlus project decreases very little while soaking in water for up to three hours.

Recently, a team from the University of Surrey conducted experiments on BarrierPlus coatings at the Rutherford Appleton Laboratory in the United Kingdom. They scattered a beam of neutral sub-atomic particles (neutrons) from the coatings to learn more about the molecular arrangements in the coatings. The polymers were labelled with deuterium, a heavy isotope of hydrogen, by the team at the Universite Claude Bernard Lyon 1 so that the molecular structure inside the barrier coatings could be revealed.[9] They found that when the coatings were heated to higher temperatures, the stabilizing molecules from the Barrier-Plus particles organized themselves into nano-sized domains so that there was no longer a hydrophilic pathway for water travel. The structure of this new type of barrier coating is preferred over the conventional coatings that contain surfactant.

Figure 6 shows the results obtained when one of the surfactant-free $1 \mathrm{~K}$ coatings, developed in the BarrierPlus project, is soaked in liquid water for extended periods of time. After one day of immersion, the coating has absorbed approximately $17 \mathrm{wt} \%$ water, which shows it has poor suitability as a barrier coating. The stabilizing molecule on the particles in 
this formulation contains carboxylic acid $(-\mathrm{COOH})$ groups. However, when the stabilizing polymer molecule is substituted for another type of stabilizer without $-\mathrm{COOH}$, only about 2 wt.\% water is absorbed after an initial uptake when first immersed in the water.

The $1 \mathrm{~K}$ coatings technology developed within the BarrierPlus project uses particles that have chemical groups that react with molecules in the water phase (so-called crosslinkers) during the drying process. With added crosslinkers, the coating becomes harder, more scratch-resistant, and has improved barrier properties after curing.

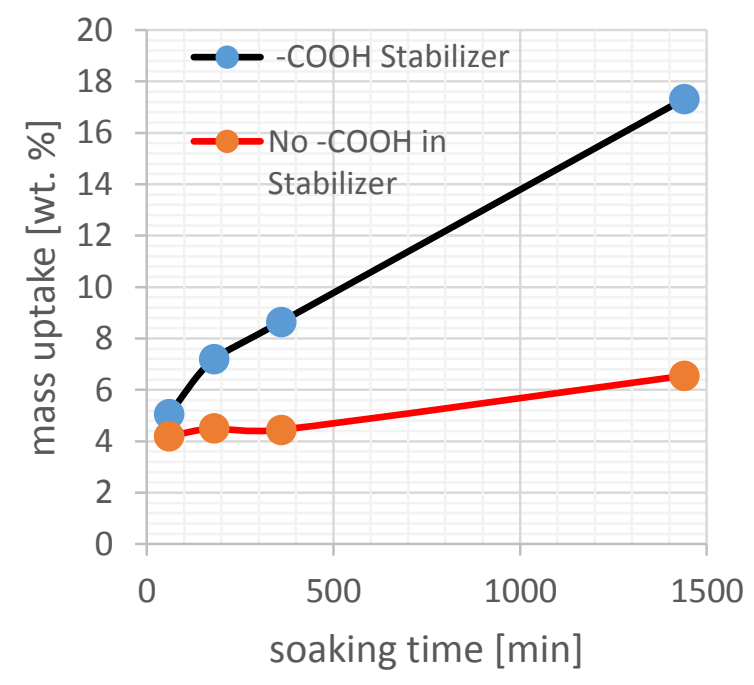

Fig. 6. A comparison of the uptake of the sorption of liquid water into BarrierPlus coatings (0.1 mm thick). Blue symbols show the results for the $1 \mathrm{~K}$ coatings that have a-COOH containing stabilizer, and the orange symbols show the same polymer composition with an alternative stabilizer.

\section{Scale-Up and Industrial Manufacturing}

The first surfactant-free particles were made in the laboratory in small quantities at the Université Claude Bernard Lyon 1. For applications as barrier coatings on steel and other substrates, much larger quantities were required. Project partners at Megara Resins successfully manufactured the particles at pilot-scale. The particles were stable in water over time were confirmed to have the same size and composition as those made in the 
laboratory. This was an important milestone for the BarrierPlus project, because it established the feasibility of industrial manufacturing.

\section{Application and Barrier Properties of High Performance Water-based Coatings}

The BarrierPlus formulations were evaluated as clear coatings and as pigmented coatings, the latter formulated with corrosion inhibitors and UV stabilisers. The initial results indicate that the hardness of the coatings is acceptable, and there is good scratch resistance.

A clear coating with a thickness between 75 and $85 \mu \mathrm{m}$ was applied onto a pigmented coating with a thickness between 90 and $120 \mu \mathrm{m}$. Both had a good film build and spray profile. Figure 7 shows a cross-sectional image of the coatings on blasted steel. Long-term natural weathering tests are currently underway on flat panels at the Dublin Institute of Technology. In addition to the flat panels, the BarrierPlus clear and pigmented coatings were successfully spray-coated onto miniature steel structures that were manufactured by Tuinsa Norte. The semi-cylindrical structures had weld lines and $10 \mathrm{~mm}$ holes, in order to test the coating on a variety of surfaces. Figure 7 shows one of the structures before and after spray coating.

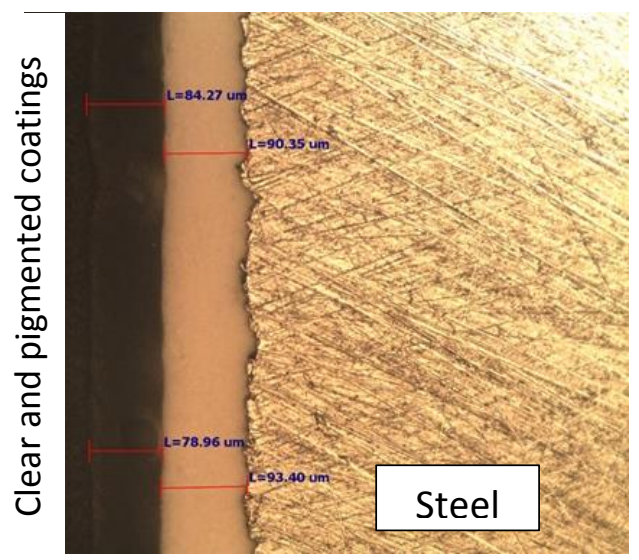

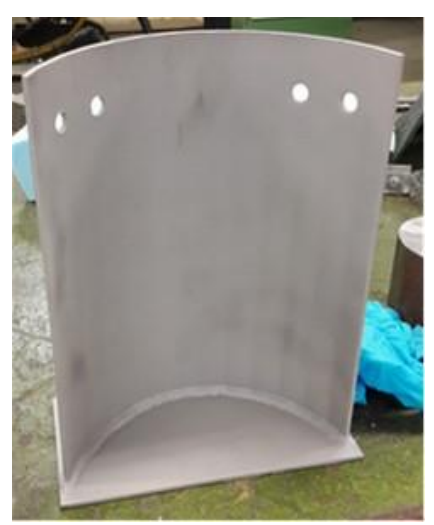

Before

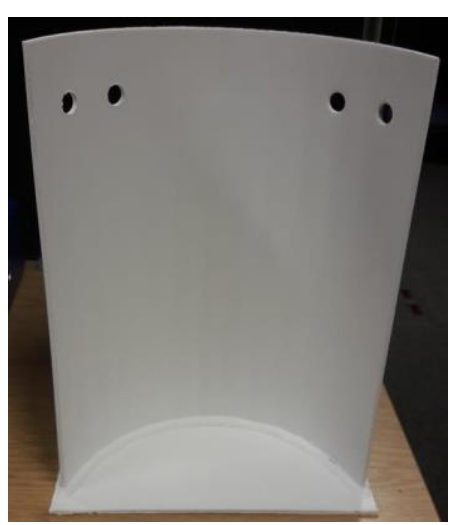

After 
Fig. 7. An optical micrograph of the cross-section of a clear topcoat on a pigmented base coat on a blasted steel panel (at left). A miniature steel structure is shown before and after the spray application of a pigmented coating (at right).

\section{Life Cycle Assessment of BarrierPlus Coatings}

An environmental impact assessment was completed for the BarrierPlus coating. A Life Cycle Assessment (LCA) compared the experimental coating against three commercially-available, benchmark coatings systems: one solvent-borne and two waterborne. The LCA followed best-practices for the industry, leveraged published Environmental Product Declarations for the benchmark products, and was conformant with ISO 14040 and 14044, with the exception of validation by an external third party. The assessment was cradle-to-grave in scope and used the CML and USETox Life Cycle Impact Assessment (LCIA) methods. The relative results of each product system are shown in Figure 8. In this assessment, all product systems were assumed to have equal performance. When comprehensive performance and durability data are available for the BarrierPlus technology, the LCA models will be refined and reassessed so that more specific environmental claims may be considered.

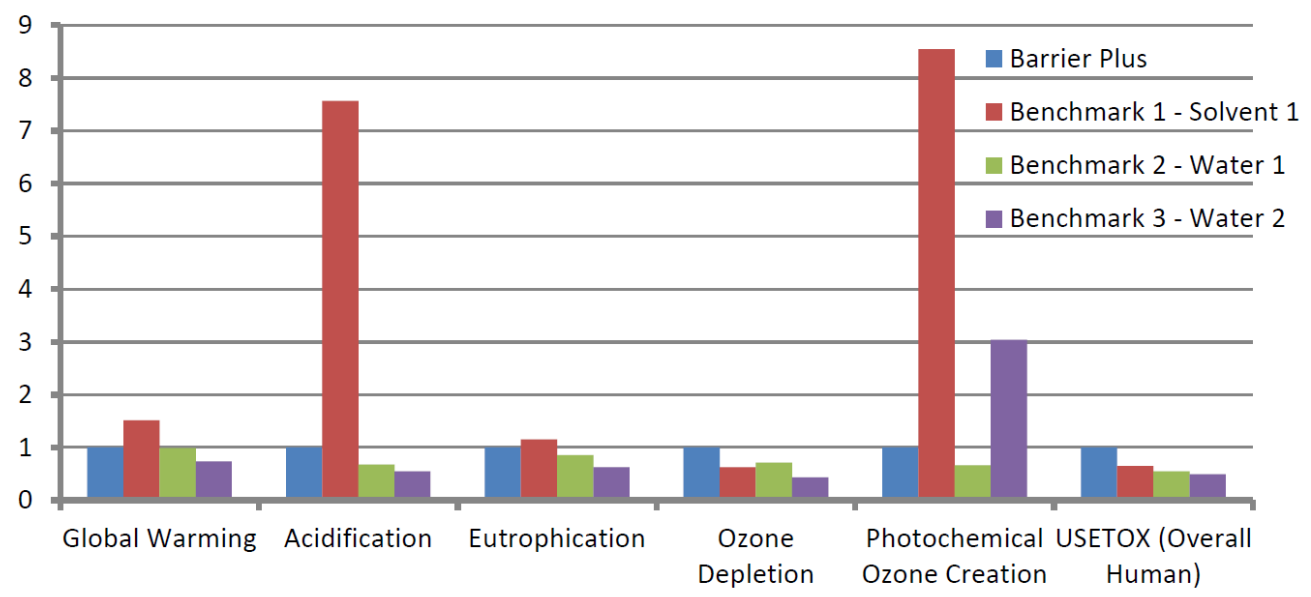


Fig. 8. Relative LCA results for three benchmark coatings (one solvent-borne and two waterborne) normalised against a BarrierPlus coating in six categories. This assessment assumes equal performance for the four products.

The BarrierPlus coating was determined to have a significantly better environmental profile than the solvent-based product system and a comparable profile to the benchmark water-based systems. In general, the impacts for the Barrier Plus coating tended to be overestimated, as conservative assumptions were made regarding its chemistry and also given that it was only produced at relatively small scale. Unfortunately, it was found that the benefits of reduced surfactant levels were not able to be captured by the LCA models and USETox, but may be a key consideration given current market and regulatory pressures. Within the scope of the current analysis, it was encouraging that the initial LCIA results for Barrier Plus coatings showed a better environmental profile than the benchmark solventborne coating system.

\section{Conclusions}

A one-component, water-based corrosion protective coating has been developed for structural steel. The waterborne polymer used in the coating was manufactured without the use of conventional surfactants. This one-component system avoids the use of isocyanates, which are commonly used in two-component polyurethane coatings. Moreover, its VOC content is significantly lower compared to a solvent-borne coating. Clear and pigmented coatings were successfully applied to steel structures. A life cycle assessment confirmed that the environmental profile of the coatings is better than a solvent-borne benchmark coating. Further work will be required to optimize the BarrierPlus technology for potential commercialization. 


\section{Acknowledgments}

Funding for this work was provided by the European Commission's Seventh Framework Programme (FP7) (Grant FP7-SME-2012-304758).

Key words: corrosion; coatings; waterborne; barrier properties; life cycle assessment

\section{References}

[1] Barton, K., Protection Against Atmospheric Corrosion: Theories and Methods, Wiley London: 1976.

[2] IRFAB, Global Industrial Coatings Markets 2010-2020, 116.

[3] NACE International, International Measures of Prevention, Application and Economics of Corrosion Technology (IMPACT) study, 2016.

[4] Directive 2004/42/CE of the European Parliament and of the Council of 21 April 2004 on the limitation of emissions of volatile organic compounds due to the use of organic solvents in certain paints and varnishes and vehicle refinishing products and amending Directive 1999/13/EC. In EUR-Lex - 32004L0042, 2004.

[5] Keddie, J. L.; Routh, A. F., Fundamentals of Latex Film Formation: Processes and Properties. Springer Dordecht Netherlands: 2010.

[6] Butler, L. N.; Fellows, C. M.; Gilbert, R. G., Effect of surfactant systems on the water sensitivity of latex films. J. Appl. Polym. Sci. 92 (2004) 1813.

[7] Velasquez, E.; Rieger, J.; Stoffelbach, F.; D'Agosto, F.; Lansalot, M.; Dufils, P.-E.; Vinas, J., Surfactant-free poly(vinylidene chloride) latexes via one-pot RAFT-mediated aqueous polymerization. Polymer, 106 (2016) 275. 
[8] Liu, Y.; Gajewicz, A.M.; Rodin, V.; Soer W.-J.; Scheerder, J.; Satgurunathan, G.;

McDonald, P.J.; Keddie, J.L. Explanations for water whitening in secondary dispersion and emulsion polymer films. J. Polym. Sci.: Polym. Phys. 54 (2016) 1658.

[9] Joanicot, M.; Wong, K.; Richard, J.; Maquet, J.; Cabane, B. Ripening of Cellular Latex Films. Macromolecules. 26 (1993) 3168. 